\title{
Optimal Design of a Benzyl Alcohol Process*
}

\author{
by Koichi Kato**, Keishi Namikawa*** and Masami Watanabe****
}

\begin{abstract}
Summary : 1 new three stage process to produce benzyl alcohol from toluene has been developed as a semi-pilot scale plant. The third stage, that is the hydrogenation of methyl benzoate to benzyl alcohol, is discussed in this article.

Thus the study for the optimal design of the hydrogenation stage has been made on the basis of experimental process data and collected cost data. Consequently, distinguishing features of hydrogenation of methyl benzoate in commercial operation are found as shown below:

1. Reactor, hydrogen bubbling column

2. Catalyst used, copper chromium type

3. Solvent, constant b.p. mixture of methanol/toluene

4. Catalyst recovery, pressure drum filter

5. Reaction temperature, $140^{\circ} \mathrm{C}$

6. Reaction pressure, $250 \mathrm{~kg} / \mathrm{cm}^{2} \cdot G$

7. Solvent ratio, $1.96 \mathrm{~kg} /$ benzoate $\mathrm{kg}$

8. Catalyst ratio, $0.132 \mathrm{~kg} /$ benzoate $\mathrm{kg}$

9. Hydrogen superficial relocity, $1.0 \mathrm{~cm} / \mathrm{sec}$

10. Conversion, ca. $30 \%$

11. Selectivity, $95 \%$

The new process produces benzyl alcohol of $99.9 \%$ purity at a price less than $200 \mathrm{yen} / \mathrm{kg}$ at a production capacity of 600 tons/30 days.
\end{abstract}

\section{Introduction}

Nowadays a rather limited amount of benzyl alcohol is being used in soap, perfume, flavour, medical and some other industries ${ }^{1)}$. The alcohol with high solvent properties, however, will be used in a large amount in paint and dyeing industries as well, provided the price of the alcohol comes down to the level of conventional solvents.

A new basic technology producing benzyl alcohol from toluene has been developed to semipilot scale at the Technical Research Center of Nippon Mining Co., Ltd. ${ }^{2), 3)}$, in an effort to offer cheaper benzyl alcohol. The new process consists of three stages. The first stage is oxidation of toluene to benzoic acid in the presence of cobalt catalyst. The second stage is esterification of benzoic acid to methyl benzoate. The final stage is hydrogenation of the benzoate to benzyl alcohol in the presence of our newly developed catalyst ${ }^{4}$.

* Received May 23, 1972.

** Mizushima Refinery, Nippon Mining Co., Ltd. (Kurashiki, Japan)

*** Research and Devclopment Division, Nippon Mining Co., Ltd.

**** Kashima Refinery, Kashima Oil Co., Ltd.
1. $\mathrm{C}_{6} \mathrm{H}_{5} \mathrm{CH}_{3}+\mathrm{O}_{2} \rightarrow \mathrm{C}_{6} \mathrm{H}_{5} \mathrm{COOH}+\mathrm{H}_{2} \mathrm{O}$

2. $\mathrm{C}_{6} \mathrm{H}_{5} \mathrm{COOH}+\mathrm{CH}_{3} \mathrm{OH} \rightarrow \mathrm{C}_{6} \mathrm{H}_{5} \mathrm{COOCH}_{3}$ $+\mathrm{H}_{2} \mathrm{O}$

3. $\mathrm{C}_{6} \mathrm{H}_{5} \mathrm{COOCH}_{3}+2 \mathrm{H}_{2} \rightarrow \mathrm{C}_{6} \mathrm{H}_{5} \mathrm{CH}_{2} \mathrm{OH}$ $+\mathrm{CH}_{3} \mathrm{OH}$

There are several commercial technologies that have been introduced for the first and second stage reactions, but none for the final stage reaction. Moreover, the final stage reaction is responsible to large proportion (as high as seventy percent) of the production cost of benzyl alcohol. Thus, the discussion in this paper is concentrated mainly on the final stage reaction, though the investment costs for oxidation and esterification processes which may be slightly affected by the selectivity of benzyl alcohol are taken into consideration.

The hydrogenation stage consists of three sections, namely, reaction section, catalyst recovery section for catalyst separation and recovery, and distillation section for solvent recovery and purification of the product. Each section is shown in Figs. 1 $\sim$ 3, respectively.

A backmixing type bubbling column is used as a reactor because of its high-mixing properties. Fecd slurry (methyl benzoate and catalyst) and 


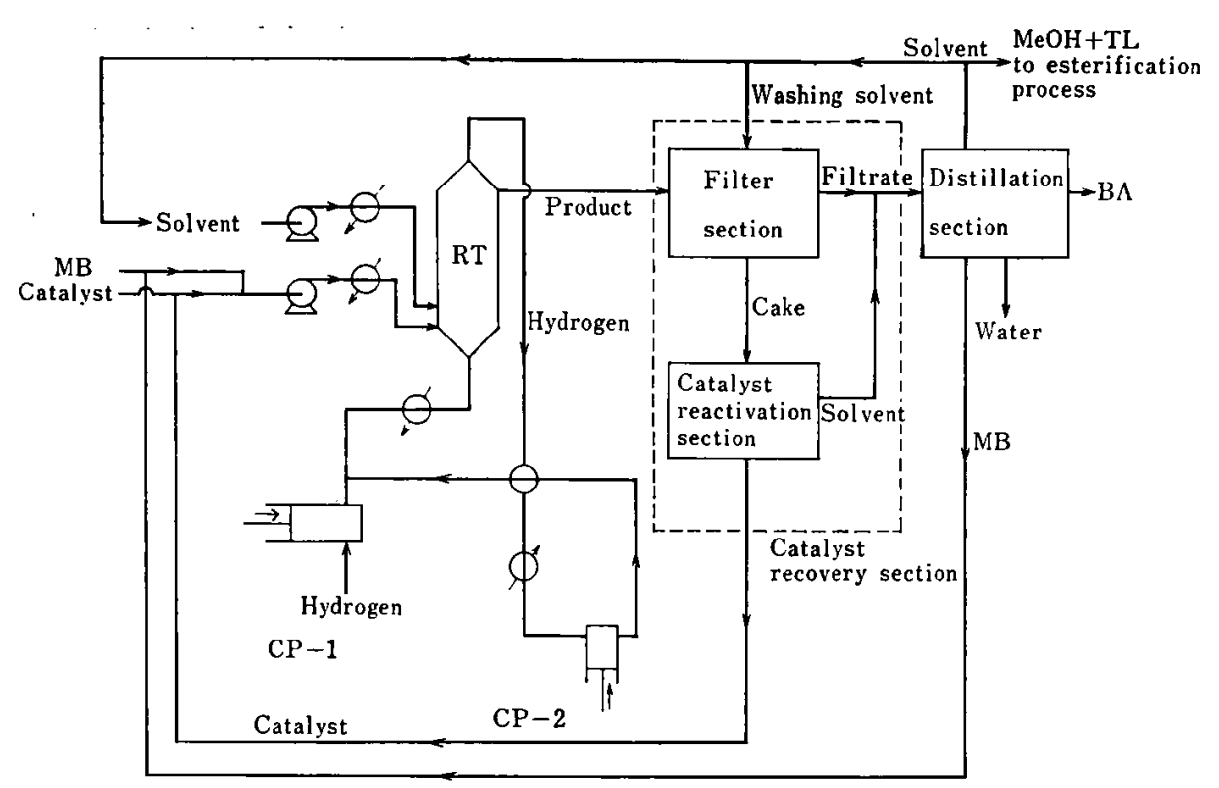

Fig. 1 Schematic Diagram of Hydrogenation Process

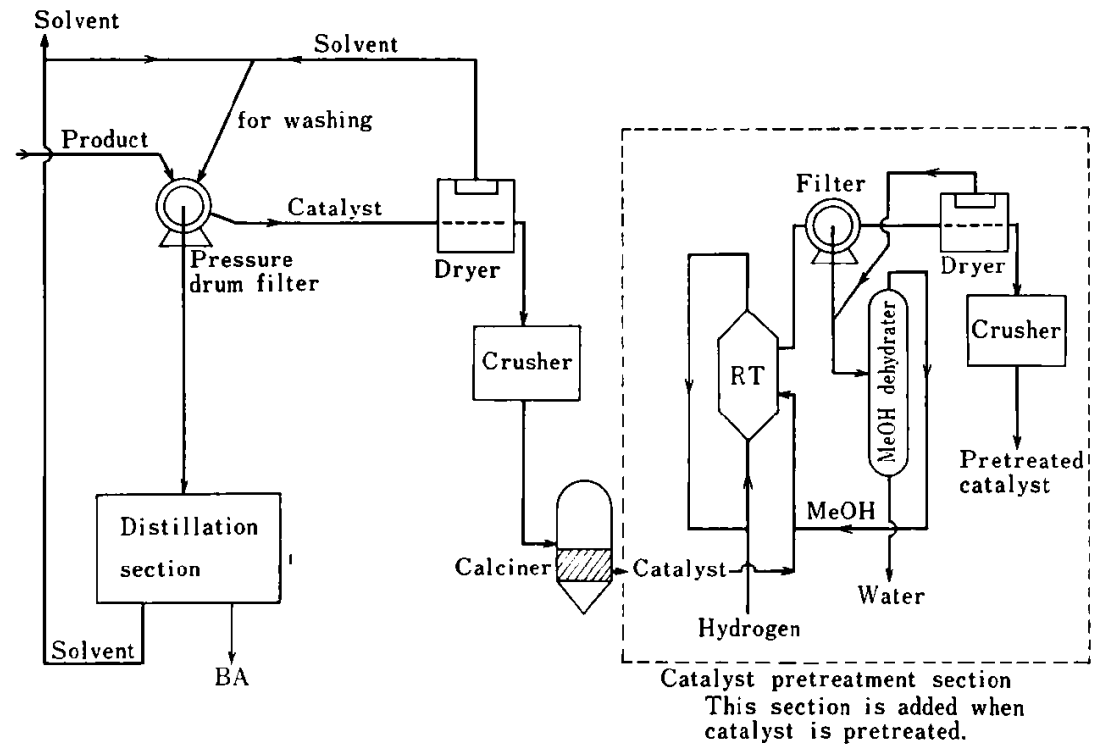

Fig. 2 Schematic Diagram of Catalyst Recovery Section

the solvent are pumped to the reactor continuously. Hydrogen gas is blown into the column at the bottom and recycled to suspend the catalyst powder in the reactive solution.

The reaction is usually carried out at a temperature in the range of 130 to $170^{\circ} \mathrm{C}$ under pressure higher than $100 \mathrm{~kg} / \mathrm{cm}^{2}$. G. The overall yield of this reaction is very high and the product does not contain any chlorides (99.9 wt $\%$ purity).

The reactor effluent is sent to the continuous drum filter, and separated catalyst cake is dried and reactivated in the stirred fluidized bed cal-

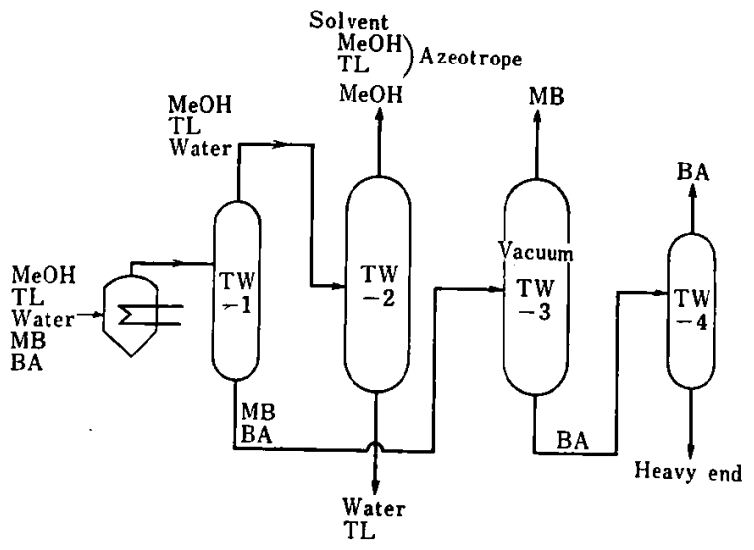

Fig. 3 Schematic Diagram of distillation section

Volume 14, No. 2, November 1972 
ciner and then recycled to the feed. The filtrate is led to a distillation section to purify the product and to recover the solvent. Recovered solvent is recycled to the feed.

\section{Preliminary Process Optimization}

Simply stated, the present problem is to carry out the optimal design for the catalytic hydrogenation of methyl benzoate. The variables to be optimized include reactor type and dimensions, reaction temperature, reaction pressure, conversion, solvent demand, catalyst demand, filter type and size, system configuration and size of distillation columns, etc.

While the process system of the oxidation and esterification stages is fixed as in pre-designed suitable manner, only the capacity and materials and utilities consumptions in those stages might be somewhat affected by the design of the hydrogenation stage.

Hydrogenation is taken place as the following consecutive reactions.

$$
\begin{aligned}
& \mathrm{MB}+2 \mathrm{H}_{2} \stackrel{K_{1}}{\longrightarrow} \mathrm{BA}+\mathrm{MeOH} \\
& \mathrm{BA}+\mathrm{H}_{2} \stackrel{K_{2}}{\longrightarrow} \mathrm{TL}+\mathrm{H}_{2} \mathrm{O}
\end{aligned}
$$

where MB stands for methyl benzoate, BA for benzyl alcohol, $\mathrm{MeOH}$ for methanol, and TL for toluene, respectively.

Several variables are optimized a priori within some specified regions from the limitations of the process and from reaction conditions.

Our experimental studies have shown that the overall rate of the first reaction is second order with respect to the concentration of $\mathrm{MB}$, and that of the second reaction is first order of BA. Activation energy of the first step is ca. $12 \mathrm{kcal} / \mathrm{mol}$ and that of the second is ca. $30 \mathrm{kcal} / \mathrm{mol}$.

High reaction temperatures lead to high reaction rate, reducing the reactor volume and its cost, but cause adverse effects on BA selectivity and the utilities.

The rate constant $K_{1}$ increases in proportion to the hydrogen pressure while $K_{2}$ is assumed to be independent of it. A higher pressure increases installation cost of the reactor and the compressors. Thus, the reaction temperature and pressure are selected a priori considering preliminary results in the range of $130^{\circ} \mathrm{C}$ to $170^{\circ} \mathrm{C}$, and under the range of 150 to $250 \mathrm{~kg} / \mathrm{cm}^{2} \cdot \mathrm{G}$.

Usually surface reaction is controlling. The superficial velocity of hydrogen gas, $v$ does not affect the overall reaction rate. Therefore $v$ is fixed as low as possible to suspend catalyst, i.e. at $1 \mathrm{~cm} / \mathrm{sec}$. MB conversion is important on the point of the capacity of the recovery sections. Higher conversion makes cost of reactor section higher and that of the recovery sections lower. Solvent ratio and catalyst ratio, which are weight ratio to $\mathrm{MB}$ in the feed slurry, have also great effect on $K_{1}$ and $K_{2}$, as well as the recovery costs.

The catalyst is such a fine particle size that the usual solid-liquid separators, such as centrifuges, auto-filter press, cannot be operated efficiently in our process. Several experiment led us to choose Fest filter, which gives pressure driving filtration under $3 \mathrm{~kg} / \mathrm{cm}^{2} \cdot \mathrm{G}$.

The initial and the running costs in the distillation section depend on the flow rate and the composition of the reactor effluent. The flow scheme of the section is, at first, determined by preliminary calculations as shown in Fig. 3 to minimize heat comsumptions and the number of columns. Then vapor-liquid equilibriums are studied experimentally to give basis of more exact considerations which are included in the optimal design calculation.

The separation of $\mathrm{MB}$ and $\mathrm{BA}$ is best carried out under vacuum, ca. $60 \mathrm{mmHg}$, since the relative volatility increases with decrease in temperature, and low temperature prevents the formation of benzyl benzoate in the columns.

\section{Permissible Region of the Variables}

These initial studies, followed by tentative design calculations, determined the region of variables to be optimized finally as follows (explained later).

Solvent ratio

$$
\begin{aligned}
& S_{R} \quad 1.954 \sim 4.303 \quad \mathrm{~kg} / \mathrm{MBkg} \\
& -1 \leq x_{1} \leq 1
\end{aligned}
$$

Reaction temperature

$$
T 140 \sim 160 \quad{ }^{\circ} \mathrm{C}
$$

$$
-1 \leq x_{2} \leq 1
$$

Solvent composition

$$
\begin{aligned}
& S_{c} \quad 0.044 \sim 0.13 \quad \text { TLmol/MeOHmol } \\
& -1 \leq x_{3} \leq 1
\end{aligned}
$$

Catalyst ratio

$$
\begin{gathered}
C_{R} 0.132 \sim 0.263 \quad \mathrm{~kg} / \mathrm{MBkg} \\
-1 \leq x_{4} \leq 1
\end{gathered}
$$

Reaction pressure

$$
\begin{aligned}
& P \\
& \quad 150 \sim 250 \quad \mathrm{~kg} / \mathrm{cm}^{2} \cdot \mathrm{G} \\
& -1 \leq x_{5} \leq 1
\end{aligned}
$$

where, $x_{1} \quad(i=1 \sim 5)$, are the dimensionless variables whose absolute values are unity at the 
both limits of each of the Ivariables.

It is restricted to make the region wider by considering the errors of the experimental data and of its formulation.

The objective function, $O_{F}$ is defined as total production cost of $\mathrm{BA}$, which covers oxidation, esterification and hydrogenation stages. $O_{F}$ consists of fixed charge, $E_{q}$, utilities cost, $U_{t}$ and materials cost, $M_{t}$ (Refer Eq. (20)).

The minimum point of the objective function is explored by the steepest decent $\operatorname{method}^{5), 6)}$, as well as by the Box-Wilson $\operatorname{method}^{7)}$, while keeping the following variables constant: $\mathrm{H}_{2}$ velocity $v(=1.0 \mathrm{~cm} / \mathrm{sec})$ and production capacity $C_{a p}(=333$ and $1,000 \mathrm{~kg} / \mathrm{hr}$.

\section{Formulation of the Equations 4.1 Reaction Rate}

The consecutive reactions, mentioned previously are expressed by the following equations.

$$
\begin{aligned}
& -\frac{d(\mathrm{MB})}{d \theta}=k_{1} P_{\mathrm{H}_{2}}{ }^{l}(\mathrm{MB})^{m} \\
& \frac{d(\mathrm{BA})}{d \theta}=k_{1} P_{\mathrm{H}_{2}}{ }^{l}(\mathrm{MB})^{m}-k_{3} P_{\mathrm{H}_{2}}{ }^{j}(\mathrm{BA})^{n} \\
& (\mathrm{MB})=(\mathrm{MB})_{0}, \quad(\mathrm{BA})=0, \text { at } \theta=0
\end{aligned}
$$

It was found $l=1, m=2, j=0$ and that $n=1$, from batchwise experiments ${ }^{8}$. Thus, Eqs. (1) and (2) are rewritten as,

$$
\begin{aligned}
& -\frac{d(\mathrm{MB})}{d \theta}=k_{1} P_{\mathrm{H}_{2}}(\mathrm{MB})^{2} \\
& \frac{d(\mathrm{BA})}{d \theta}=k_{1} P_{\mathrm{H}_{2}}(\mathrm{MB})^{2}-k_{2}(\mathrm{BA})
\end{aligned}
$$

Eqs. (3) and (4) are reformed to Eqs. (5) and (6) by using some of the following definitions.

$$
\begin{aligned}
& \text { Conversion: } \quad C=1-\frac{(\mathrm{MB})}{(\mathrm{MB})_{0}} \\
& \text { Sclectivity: } S=\frac{(\mathrm{BA})}{(\mathrm{MB})_{0}-(\mathrm{MB})} \\
& K_{1}=k_{1} P_{\mathrm{H}_{2}}(\mathrm{MB})_{0} \\
& K_{2}=k_{2} \\
& \frac{d C}{d \theta}=K_{1}(1-C)^{2} \\
& \frac{d(C S)}{d \theta}=K_{1}(1-C)^{2}-K_{2} C S \\
& C=0 \quad S=1, \quad \text { at } \theta=0
\end{aligned}
$$

These are basic equations. The integration of Eq. (5) is expressed by,

$$
K_{1} \theta=C /(1-C)
$$

Dividing Eq. (6) by Eq. (5), the following equation, then $\mathrm{Eq} .(8)$ is obtained.

$$
\frac{d(C S)}{d C}=\frac{K_{1}(1-C)^{2}-K_{2} C S}{K_{1}(1-C)^{2}}
$$

$$
C \frac{d S}{d C}+K \frac{C S}{(1-C)^{2}}+S=1
$$

where $K=K_{\mathrm{g}} / K_{1}$, and is considered to be a kind of selectively parameter. Eq. (8) can be solved analytically as,

$$
\begin{aligned}
S & =\frac{1}{C}\left[C-1+\exp \left(\frac{K}{C-1}\right)\left\{K E i\left(\frac{K}{1-C}\right)\right.\right. \\
& -K E i(K)+\exp (K)\}]^{*)}
\end{aligned}
$$

The curves in Fig. 4 which show the relation among $C, S$ and $K$ are obtained by Eq. (9).

$K_{1}$ and $K_{2}$ are obtained by wide range of batchwise experimental data in such a way that at first $K_{1}$ is calculated by Eq. (7), and then $K$ is found in Fig. 4, finally $K_{2}$ is determined.

Then using the symmetrical composite design method $^{9)}, K_{1}$ and $K_{2}$ are formulated in the following manner as functions of four variables (which are stated in 3$)^{10}$.

$$
\begin{aligned}
K_{1}= & \left(0.2363+0.0251 x_{1}+0.0318 x_{2}-0.0079 x_{3}\right. \\
+ & 0.0798 x_{1}-0.0053 x_{1}{ }^{2}+0.0027 x_{2}{ }^{2}-0.0068 x_{3}{ }^{2} \\
& -0.0112 x_{4}{ }^{2}+0.0141 x_{1} x_{2}-0.0010 x_{1} x_{3} \\
& +0.0202 x_{1} x_{4}+0.0093 x_{2} x_{3}+0.0134 x_{2} x_{4} \\
& \left.+0.0163 x_{3} x_{4}\right) \times\left(1.340+0.333 x_{5}\right) \\
K_{2}= & 0.0571-0.0072 x_{1}+0.00219 x_{2}+0.0045 x_{3} \\
& +0.0053 x_{4}-0.0003 x_{1}{ }^{2}+0.0027 x_{2}{ }^{2} \\
& -0.0042 x_{3}{ }^{2}-0.0020 x_{4}{ }^{2}-0.0043 x_{1} x_{2} \\
& -0.0031 x_{1} x_{3}-0.0051 x_{1} x_{4}+0.0022 x_{2} x_{3} \\
& +0.0069 x_{2} x_{4}+0.0012 x_{3} x_{4}
\end{aligned}
$$

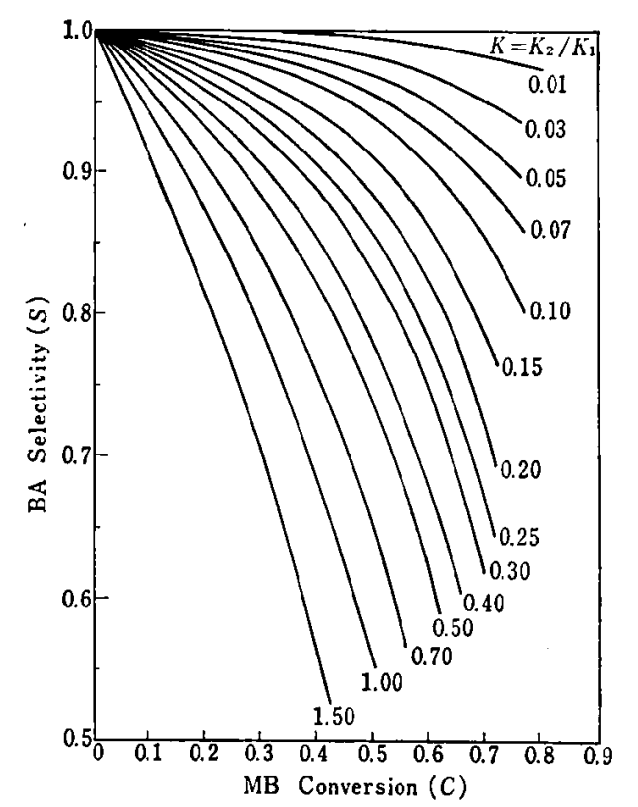

Fig. 4 Relation between $C$ and $S$ When Parameter, $K=K_{2} / K_{1}$ is Constant in Batchwise Reaction

*) $E i(x)=\int_{-\infty}^{x} e^{x} x-1 d x$

Volume 14, No. 2, November 1972 
Table 1-a Data for Filtration ${ }^{12)}$

\begin{tabular}{l|c|cc}
\hline Average specific cake resistance & $\alpha$ & $10^{13}$ & $\mathrm{~m} / \mathrm{kg}$ \\
Resistance of filter cloth & $K_{m}$ & $2 \times 10^{12}$ & $1 / \mathrm{m}$ \\
Pressure difference & $\Delta P$ & 3 & $\mathrm{~kg} / \mathrm{cm}^{2}$ \\
\hline
\end{tabular}

$\kappa$ and $\mu$ are decided in process condition.

Table 1-b Data for Distillation

\begin{tabular}{|c|c|c|c|}
\hline & TW-1 & TW-2 & TW-3 \\
\hline $\begin{array}{l}\text { Operation Pressure } \\
\text { Average Relative Volatility (between key components) } \\
\text { Feed Condition (liquid/feed) } \\
\text { Separation Condition (limit of key components in Top } \\
\text { and Bottom streams) } \\
\text { Plate Efficiency (overall) }\end{array}$ & $\begin{array}{c}760 \\
59.1 \\
0 \\
\text { Top } \mathrm{MB} 0.001 \\
\text { Bot. } \mathrm{H}_{2} \mathrm{O} 0.001 \\
\\
\quad 0.6\end{array}$ & 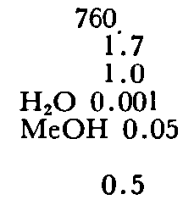 & $\begin{array}{l}60 \mathrm{mmHg} \\
2.5 \\
1.0 \\
\text { BA } 0.005 \\
\text { MB } 0.01 \\
\text { mole fraction } \\
\quad 0.5\end{array}$ \\
\hline Tray Spacing, m & \multicolumn{3}{|c|}{ Diameter of columns, m } \\
\hline $\begin{array}{l}0.30 \\
0.45 \\
0.60\end{array}$ & \multicolumn{3}{|c|}{$\begin{array}{l}\text { less than } \\
\text { more than }\end{array}$} \\
\hline
\end{tabular}

Table 1-c Data for Galcination

\begin{tabular}{l|l}
\hline Type & Stirred fluidized bed \\
Temperature & $450 \pm 20^{\circ} \mathrm{C}$ in air \\
Air Velocity & $0.80 \mathrm{~cm} / \mathrm{sec}$ \\
Solid Retention Time & $2.5 \mathrm{hrs}$ \\
Bed Height/Diameter & 1.6 \\
Number of Impellers & 1 \\
Stirring Speed & $50 \mathrm{rpm}$ \\
\hline
\end{tabular}

\subsection{Other Technical Data and Equations}

The rate of filtration of the slurry can be expressed as the following equation.

$$
\frac{d v}{d \theta}=\frac{k}{2(v+c)}
$$

where,

$$
\left.\begin{array}{l}
k=\frac{2 \Delta P g_{c}}{\alpha \mu} \\
c=\frac{K_{m} \kappa}{\alpha}
\end{array}\right\}
$$

The symbols $\alpha$ and $K_{m}$ represent the average specific cake resistance and the resistance of unit area of filter cloth, respectively. Solving Eq. (12) filter size can be determinded ${ }^{11)}$ using the values shown in Table 1 -a.

For the distillation columns activity coefficients are studied in the approximate compositions near the feed, top and bottom positions, and then formulated to equations. The number of trays and reflux ratios for distillation columns can be determinded by a well known calculation method using Fenske equation, Underwood equation and Gilliland correlation. In this step reflux ratios are specified as 1.5 times the minimum reflux ratios. Plate efficiencies of the columns are assumed to be suitable values between 0.5 and
0.6 on the basis of comparing similar existing towers. Then the diameters of the columns are calculated by the limitation of the allowable vapor rate which relates to tray spacing ${ }^{13}$. Main design factors required for calculation are shown in Table 1-b.

From the result of pilot plant test, the type and design factors of the calciner are determinded as given in Table 1-c. The size of calciner can be estimated by solid retention time and height/ diameter ratio.

\subsection{Cost Data}

The following eight items are basic to initial investment of the hydrogenation process: reactor, feed compressor, recycle compressor, vessels and pumps, heat exchangers, calciner, filter and distillation columns. All costs were calculated on the basis that equipment purchased and built in the Pacific coast of Japan for the year 1970. For purpose of machine computation, the following are applied to obtain the various initial costs in $10^{6}$ yen.

The costs $C_{1} \sim C_{5}$ are determined in the interpolation method: the logarithm of the cost and that of the cost variable are assumed to be in linear 
Table 2 Cost Variables and Pressure Correction Factors

\begin{tabular}{l|l|l|l}
\hline$j$ & \multicolumn{1}{|c|}{ Equipment } & \multicolumn{1}{|c}{ Cost Variables $A_{j}$} & \multicolumn{1}{|c}{ Pressure Correction $F_{j}$ Factors } \\
\hline 1 & Reactor & Internal volume $\left(\mathrm{m}^{3}\right)$ & Ratio of the thickness of cylindrical wall \\
2 & Recycle Compressor & Recycle $\mathrm{H}_{2}\left(\mathrm{Nm}^{3} / \mathrm{hr}^{\prime} \times 10^{-3}\right)$ & Ratio of power \\
3 & Feed Compressor & Feed $\mathrm{H}_{2}\left(\mathrm{Nm}^{3} / \mathrm{hr}\right)$ & Ratio of power \\
4 & Vessels and Pumps & Feed weight $(\mathrm{t} / \mathrm{hr})$ & Ratio of pressure \\
$\mathbf{5}$ & Heat Exchangers & Feed enthalpy $\left(\mathrm{kcal} /{ }^{\circ} \mathrm{C} \cdot \mathrm{hr} \times 10^{-3}\right)$ & - \\
\hline
\end{tabular}

Table 3 Practical Cost Data

\begin{tabular}{c|r|r|r|r|r|c}
\hline \multirow{2}{*}{$j$} & \multicolumn{3}{|c|}{ Cost $C_{j} 10^{6}$ yen } & \multicolumn{3}{c}{ Cost Variable $A_{j}$} \\
\cline { 2 - 7 } & Case 1 & Case 2 & Case 3 & Case 1 & Case 2 & Case 3 \\
\hline 1 & 10.58 & 91.7 & 197.4 & 1.58 & 23.1 & 56.7 \\
2 & 9.33 & 56.4 & 87.3 & 1.15 & 19.0 & 48.0 \\
3 & 5.64 & 28.2 & 45.1 & 8.98 & 150 & 374 \\
4 & 2.50 & 9.31 & 13.3 & 0.32 & 5.34 & 13.4 \\
5 & 0.63 & 8.60 & 17.8 & 0.23 & 3.86 & 9.65 \\
\hline
\end{tabular}

relation. In Table 2 are illustrated the nature of the selected cost variables and the pressure correction factors, meanwhile practical data are shown in Table 3. At first the reaction pressure is assumed at $200 \mathrm{~kg} / \mathrm{cm}^{2} \cdot G$ and the apparent cost is given by interpolation; then, multiplying pressure factors, the real cost can be obtained.

Other costs $\mathrm{C}_{6} \sim \mathrm{C}_{8}$ are formulated as follows:

Calciner and other solid handling device:

$$
C_{6}=2.69 C_{L}^{0.45}
$$

where

$$
C_{L}=\text { catalyst load }(\mathrm{kg} / \mathrm{hr})
$$

Filter :

$$
\left.\begin{array}{l}
A \geq 2 m^{2} \\
C_{7}=8.0 A^{0.63}
\end{array}\right\}
$$

where

$A=$ filtration area $\left(\mathrm{m}^{2}\right)$

Distillation columns:

$$
\begin{aligned}
& C_{8 i}=0.4 f_{i} N_{i} D_{T i}{ }^{0.4} \\
& C_{8}=\sum_{i} C_{8 i}
\end{aligned}
$$

where

$N_{i}=$ number of plates in each column (-)

$D_{T i}=$ diameter of each column (m)

$f_{i}=$ type factor depending on the column (-)

Thus total initial investment of the process, which produces 200 tons of $\mathrm{BA}$ in a month, $T_{c}$ is expressed by, $\left.{ }^{8}\right)$

$$
\begin{aligned}
& T_{C}=(1-0.252) \sum_{j=0}^{8} C_{j}+95.6 \\
& C_{0}=96.5 S^{-0.56}
\end{aligned}
$$

where 0.252 is a compensation factor for administrative expense such as engineering cost, insurance, contingency, etc.; 95.6 is a compen- sation constant for common installation cost such as storage tank, service pump, etc. $C_{0}$ stands for the total initial investment of the oxidation and esterification processes, which may be affected slightly by BA selectivity $S$.

Therefore the fixed charge on production cost, $E_{q}$ is given below

$$
E_{q}=0.1124 T_{C}
$$

where 0.1124 is a factor corresponding to depreciation rate, maintenance cost ratio, etc.

Other casts $M_{t}$ and $U_{\iota}$, for materials and utilities requirement, are directly estimated by the material and energy balances (as illustrated in Tables 5 and 6 ).

\section{Computation}

A HITAC 8400 digital computer was used in this investigation. The computer program consists of two parts. The first part, dealing with any given set of variables, calculates the objective function, that is, the total installations, utilities and materials costs, on the basis of above mentioned data and formulation. In this step various technics of chemical engineering calculation are quite useful. The process includes many recycle loops; therefore, material balance which gives flow rate and composition of the streams is given as the solution of simultaneous equations.

The second part carries out the exploration of the minimum point of the objective function. The first part is built in the second, and is operated as a subroutine program. The flow charts for these two parts are shown in Figs. 5 and 6 .

\section{Computation Results}

\subsection{Preliminary Computation}

To avoid the possibility of missing the true minimum, and to give a direction for experimental studies, a wider range was selected for the first trial, so that the desired minimum point is purposely included. The base point is not considered as an optimum in an industrial scale, but best known from prior laboratory work. In this 


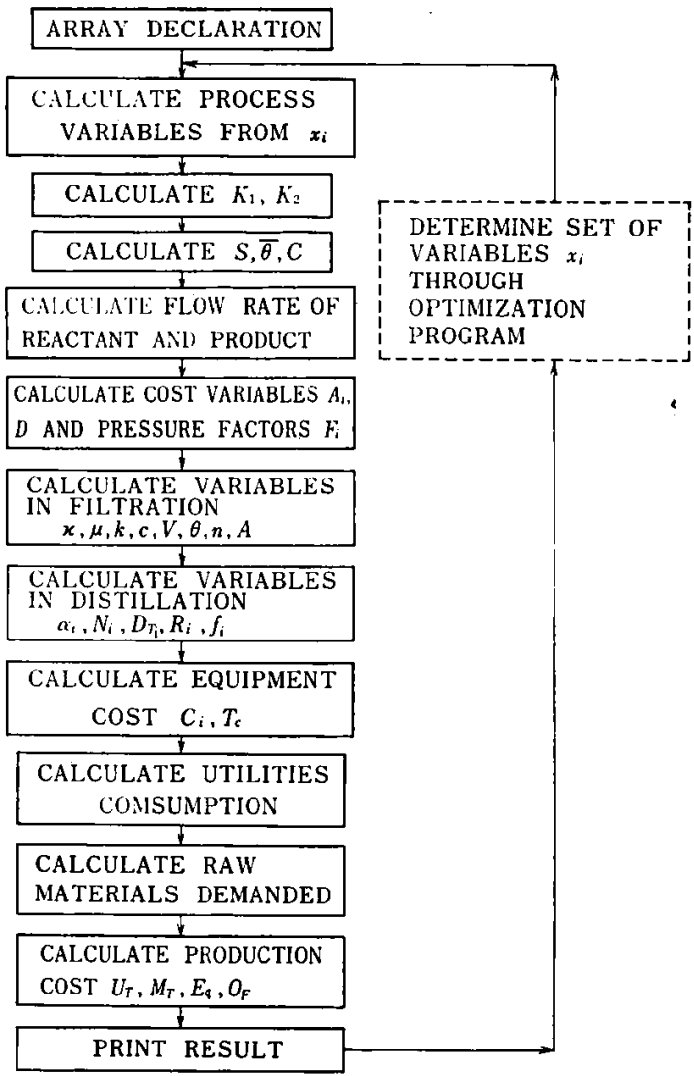

Fig. 5 Subroutine Program for Design and Cost estimation of the process

preliminary step, an approximate solution to the problem was obtained by assuming that the solvent is pure $\mathrm{MeOH}$, that $\mathrm{BA}$ selectivity is constant at 0.90 , and the installation costs except for reactor, filter and solvent recovery tower, are considered to be constant.

The composite design method proposed by Box and Wilson was used in this part of the investigation, and result was obtained as a response equation of the following canonical form.

$$
\begin{aligned}
O_{F} & =152.8+5.2 x_{1}{ }^{2}+4.5 x_{2}{ }^{2}+7.5 x_{3}{ }^{2} \\
& +6.1 x_{4}{ }^{2}+3.0 x_{5}{ }^{2}
\end{aligned}
$$

As the coefficients of the variables in the above equation are all positive, moving away from the optimal point in any direction will cause an increase in cost. The coefficients also represent sensitivity of each variable; $\Psi$.

They are in the following order. $\Psi_{3}>\Psi_{4}>$ $\Psi_{1}>\Psi_{2}>\Psi_{5}$. The more the sensitivity that is observed in a variable, the more careful consideration is required for the variable.

Apparently $\Psi$ also depends on the width of each variable range and the region of each variable is determined by taking this into consideration.

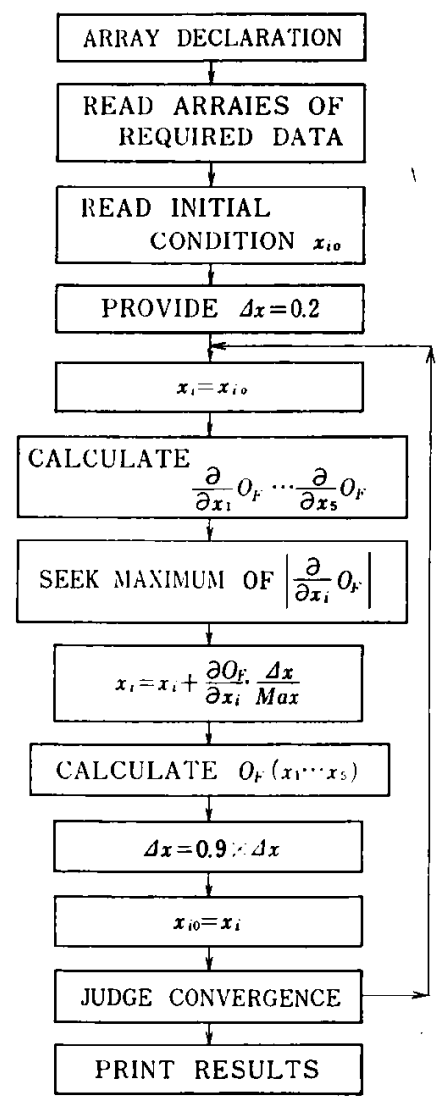

Fig. 6 Optimization Program Based on Steepest Decent Method

\subsection{Approach to Optimization}

Eq. (21) suggests that the response surface is not a saddle type but very monotonous. This leads us to say that the steepest decent method is quite adequate to find an optimum. Therefore in the following part, this method is solely employed.

6.2.1 Case of Wider Region $\left(-2 \leq x_{i} \leq 2\right.$, $i=1,2, \cdots 5$ )

In the case of the wider region $\left(-2 \leq x_{1} \leq 2\right.$, $i=1,2, \cdot 5$ ), the optimal point is given as shown in Table 4. This result is obtained with none of those assumptions in the preceding section.

The optimal point, however, is quite far from the base point and the reliability of the formula is now open to question. In fact the experiment

Table 4 Optimal Point in Case of Wider Region $C_{a p}=333.3 \mathrm{~kg} / \mathrm{hr}$

\begin{tabular}{llll}
\hline$x_{1}$ & $\left(S_{R}\right)$ & -2 & $(0.814)$ \\
$x_{2}$ & $(T)$ & -2 & $(130)$ \\
$x_{3}$ & $\left(S_{C}\right)$ & -0.888 & $(0.488)$ \\
$x_{4}$ & $\left(C_{R}\right)$ & -1.723 & $(0.084)$ \\
$x_{5}$ & $(P)$ & -0.010 & $(200)$ \\
$O_{F}$ & & 131.2 & \\
\hline
\end{tabular}

Bulletin of The Japan Petroleum Institute 
Table 5 Performance and Costs at Optimal Condition

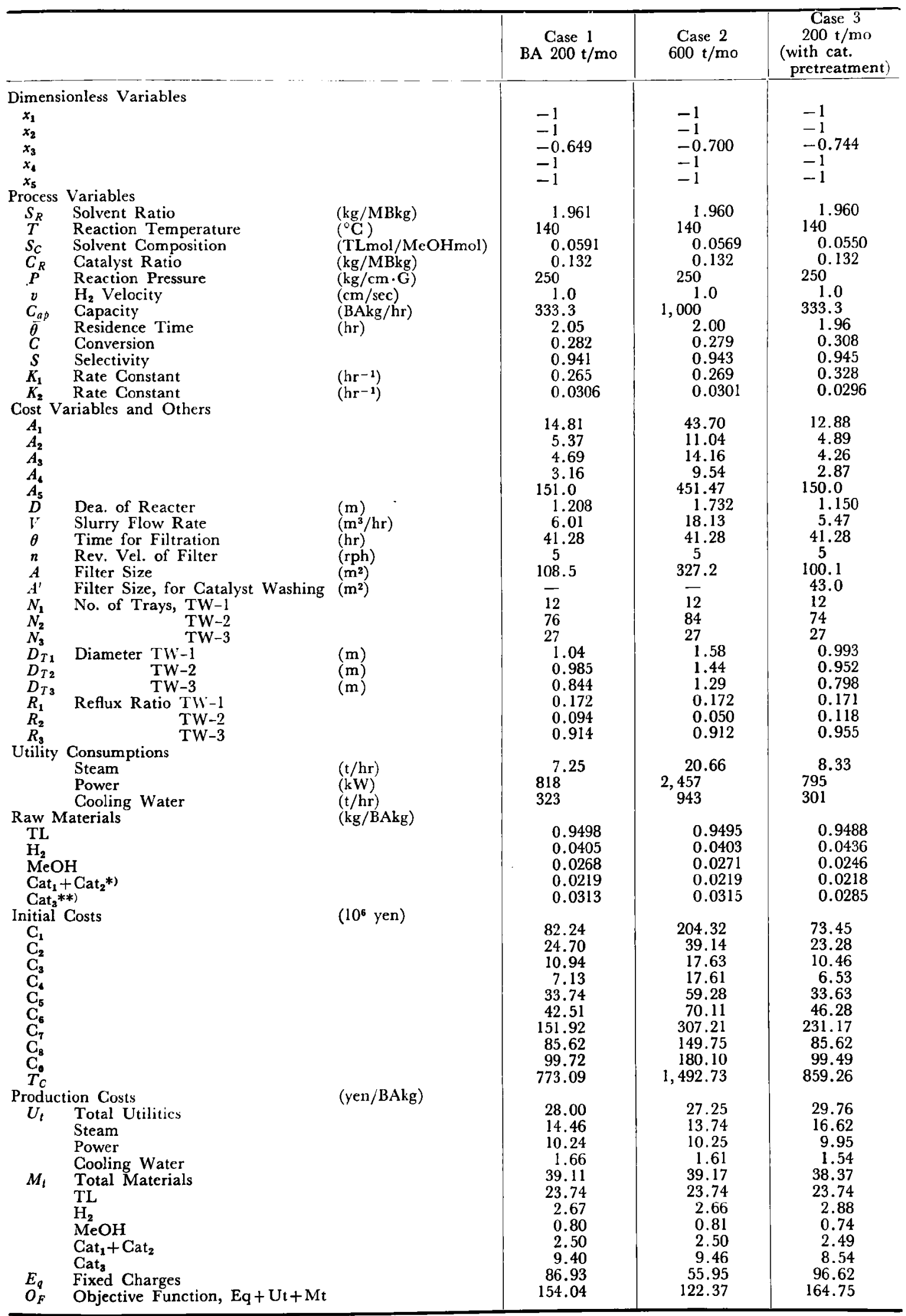

*) Catalyst for oxidation and esterification.

**) For hydrogenation. 
failed to trace a value of $K_{1}$ from the formula on the optimal point. Therefore, the region is reduced, and the formulas arc corrected as Eqs. (10) and (11) for further studies.

\subsubsection{Case of Limited Region $\left(-1 \leq x_{i} \leq 1\right.$, $i=1,2, \cdots 5$ )}

The final result, an optimal set of variables, accompanied by other major parameters arc obtained and shown in Table 5. At the optimal condition, calculated kinetic rate data were verified by experiment.

The variables except $x_{3}$ slip the true minimum point out of their limited range, however, the terminal point may be still regarded as an optimum due to certain process restrictions, such as catalyst life and ease or stability of the plant operation. The nature of response surface in

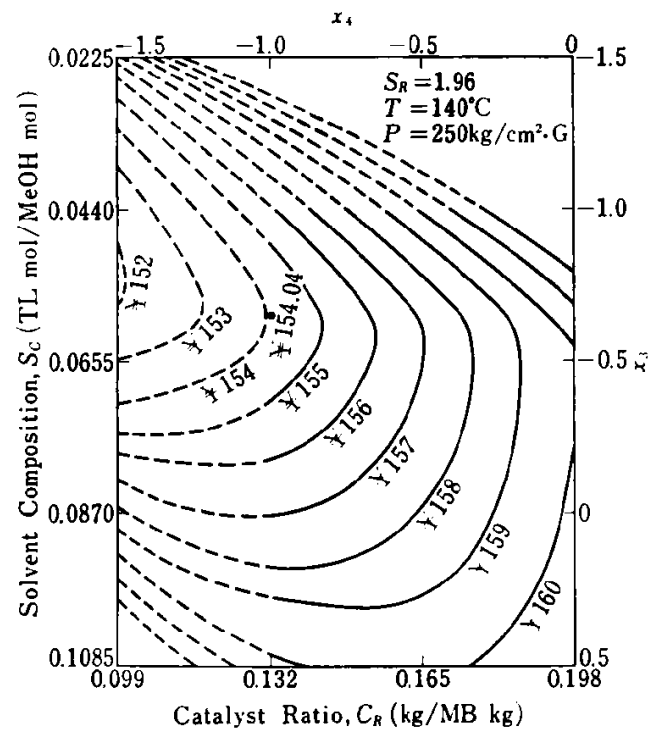

Fig. 7 Cost Contours Near the Optimal Point $\left(S_{R}, T, P\right.$, Constant $)$ the neighborhood of the optimal point is illustrated in Figs. 7 to 9.

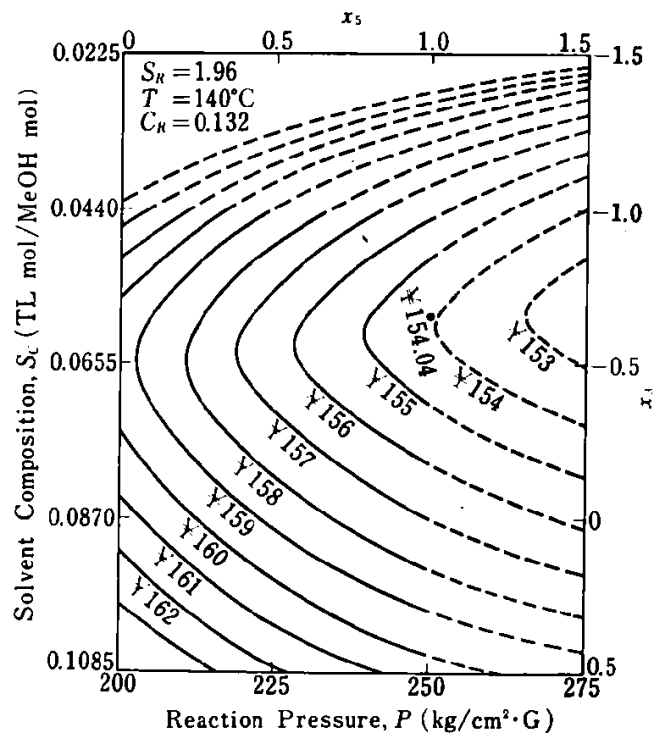

Fig. 8 Cost Contours Near the Optimal Point $\left(S_{R}, T, C_{R}\right.$, Constant)

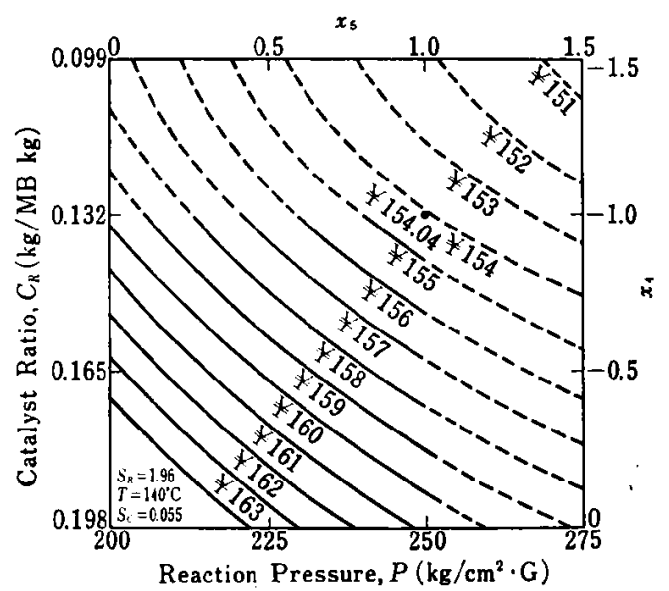

Fig. 9 Cost Contours Near Optimal Point $\left(S_{R}\right.$, $T, S_{C}$, Constant)

Table 6 Production Cost Estimate

\begin{tabular}{|c|c|c|c|}
\hline $\begin{array}{c}\text { Plant Scale } \\
\text { BA } t / m o\end{array}$ & $\begin{array}{c}\text { Case 1 } \\
200 \\
\text { No Pretreatment }\end{array}$ & $\begin{array}{c}\text { Case 2 } \\
600 \\
\text { No Pretreatment }\end{array}$ & $\begin{array}{cc}\text { Case } 3 \\
200 \\
\text { Cat. Pretreatment }\end{array}$ \\
\hline 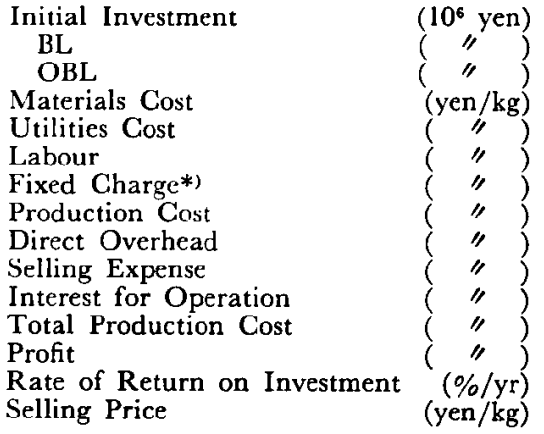 & $\begin{array}{l}914 \\
773 \\
141 \\
39.11 \\
28.00 \\
13.54 \\
86.93 \\
167.58 \\
7.25 \\
4.60 \\
6.04 \\
185.5 \\
56.0 \\
30 \\
241.5\end{array}$ & $\begin{array}{r}1,765 \\
1,493 \\
272 \\
39.17 \\
27.25 \\
4.51 \\
55.95 \\
126.88 \\
5.32 \\
4.60 \\
4.43 \\
141.2 \\
36.1 \\
30 \\
177.3\end{array}$ & $\begin{array}{l}1,015 \\
859 \\
156 \\
38.37 \\
29.76 \\
13.54 \\
96.62 \\
178.29 \\
7.78 \\
4.60 \\
6.48 \\
197.2 \\
62.1 \\
30 \\
259.3\end{array}$ \\
\hline
\end{tabular}

*) Total of such fixed charges as Maintenance (3\%/yr of BL), Depreciation $(11.25 \% / \mathrm{yr}$ of $\mathrm{BL}, 5 \% / \mathrm{yr}$ of $\mathrm{OBL})$, Interest for construction $(5 \% / \mathrm{yr}$ of $\mathrm{BL}+\mathrm{OBL})$ and Administrative expense $(5 \% / \mathrm{yr}$ of $\mathrm{BL}+\mathrm{OBL})$. 


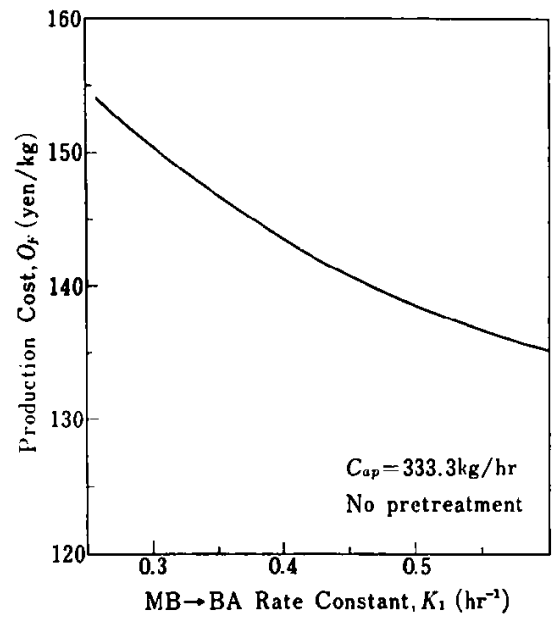

Fig. 10 Dependence of Production Cost $O_{F}$ on rate Constant $K_{1}$ Around the Optimal Point

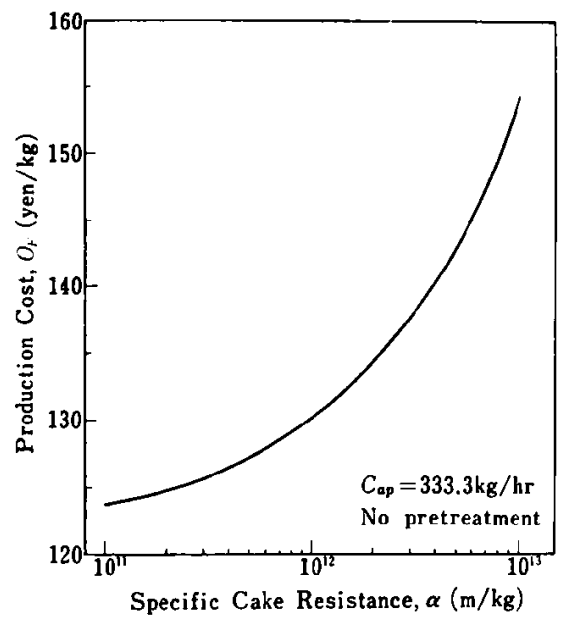

Fig. 11 Dependence of Production Cost $O_{F}$ on Filtration Resistance $\alpha$ Around the Optimal Point

Furthermore, the experimental study showed that hydrogen pretreatment of the catalyst raises its activity as much as $20 \%$, but the effect is temporaty, so that a process with such device doubles the filter and reactor requirement and is expensive. This is also considered (Table 5).

The production cost and the selling price for 200 tons/month and 600 tons/month capacities are illustrated in Table 6. The larger plant allows $25 \%$ reduction in the selling price.

\subsection{Important Process Factors}

Among the various process factors, rate constant $K_{1}$ and filtration resistance $\alpha$ have the greatest effect on the production cost. If these are improved, the cost can be reduced as illustrated in Figs. 10 and 11.
Further experimental studies are expected.

\section{Conclusions}

As the results of this investigation, features of design and operation of a process for the liquid phase hydrogenation of methyl benzoate have been obtained. These are given as follows:

1. Reactor, hydrogen bubbling column

2. Catalyst used, copper-chromium type

3. Solvent, constant b.p. mixture of $\mathrm{McOH} /$ TL

4. Catalyst recovery, high pressure drum filter

5. No catalyst pretreatment

6. Reaction temperature, $140^{\circ} \mathrm{C}$

7. Reaction pressure, $250 \mathrm{~kg} / \mathrm{cm}^{2} \cdot \mathrm{G}$

8. Solvent ratio, $1.96 \mathrm{~kg} / \mathrm{MBkg}$

9. Hydrogen superficial velocity, $1.0 \mathrm{~cm} / \mathrm{sec}$

10. Conversion, ca. $30 \%$

11. Selectivity, $95 \%$

12. Diameter of reactor, $1.73 \mathrm{~m}$

13. Height of reactor, $17 \mathrm{~m}$

The flow sheets are shown in Figs. 1 to 3.

A new benzyl alcohol process with toluene as raw material, in which catalytic hydrogenation occupies the major role, can offer benzyl alcohol at a price less than $200 \mathrm{yen} / \mathrm{kg}$ at a production capacity of 600 tons $/ 30$ days.

\section{Acknowledgement}

The authors express their appreciation to the personnel in the laboratories for their assistance, and they thank Nippon Mining Company for permission to publish this paper.

\section{Nomenclature}

$A$ : Filtration area of filter, $\mathrm{m}^{2}$

$A_{i}$ : Cost variables, $i=1 \sim 5$

$C$ : MB Conversion

$C_{n p}$ : BA Production rate, $\mathbf{k g} / \mathrm{hr}$

$C_{i}$ : Initial cost of equipment, $i=0 \sim 8,10^{6}$ yen

$C_{L}$ : Catalyst load, $\mathrm{kg} / \mathrm{hr}$

$C_{R}$ : Catalyst ratio, $\mathrm{kg} / \mathrm{MB} \mathrm{kg}$

$c$ : Parameter of filtration defined in Eq. (13), m

$D$ : Diameter of reactor, $\mathrm{m}$

$D_{T}$ : Diameter of distillation tower, $\mathrm{m}$

$E q$ : Fixed charge on production cost, ycn/BA kg

$F_{i}$ : Pressure correction factors, $i=1 \sim 4$

$f_{i}$ : Type Factors of each tower, $\mathrm{i}=1 \sim 4$

$j$ : Order of reaction, $\mathrm{BA} \rightarrow \mathrm{TL}$ respect to $\mathrm{H}_{2}$

$K$ : Selectivity parameter, $K_{2} / K_{1}$

$K_{1}$ : Rate constant, $k_{1} P_{\text {Hi } 2}(\mathrm{MB})_{0}, 1 / \mathrm{hr}$

$K_{2}$ : Rate constant, same as $k_{2}, 1 / \mathrm{hr}$

$K_{m}$ : Resistance of unit area of filter medium, $1 / \mathrm{m}$

$k$ : Parameter of filtration defined in Eq. (13), $\mathrm{m}^{2} / \mathrm{sec}$

$k_{1}$ : Rate constant $\mathrm{MB} \rightarrow \mathrm{BA}, \quad l / \mathrm{mol} \cdot \mathrm{hr}^{-1} \cdot \mathrm{cm}^{2} / \mathrm{kg}$

$k_{2}$ : Rate constant $\mathrm{BA} \rightarrow \mathrm{TL}, 1 / \mathrm{hr}$ 
$l$ : Order of reaction, $\mathrm{MB} \rightarrow \mathrm{TL}$ respect to $\mathrm{H}_{2}$

$M_{l}:$ Materials cost, yen/BA kg

$m$ : Order of reaction, $\mathrm{MB} \rightarrow \mathrm{BA}$, respect to $\mathrm{MB}$

$N$ : Number of trays in tower

$n$ : Order of reaction, $\mathrm{BA} \rightarrow \mathrm{TL}$, respect to $\mathrm{BA}$ or Revolution velocity of filter, $\mathrm{rph}$

$O_{F}$ : Objective function-production cost of $\mathbf{B A}$

$P$ : Reaction pressure, $\mathrm{kg} / \mathrm{cm}^{2} \cdot \mathrm{G}$

$P_{H_{2}}$ : Partial pressure of hydrogen, $\mathrm{kg} / \mathrm{cm}^{2} \cdot \mathrm{G}$

$J P$ : Driving pressure difference for filtration, $\mathrm{kg} / \mathrm{cm}^{2}$

$R$ : Reflux ratio

$S$ : BA Selectivity

$S_{c}$ : Solvent composition, TL $\mathrm{mol} / \mathrm{MeOH} \mathrm{mol}$

$S_{R}:$ Solvent ratio, $\mathrm{kg} / \mathrm{MB} \mathrm{kg}$

$T$ : Reaction temperature, ${ }^{\circ} \mathrm{C}$

$T_{c}$ : Total initial investment within battery limit, $10^{6}$ yen

$U_{l}:$ Utilities cost, yen/BA kg

$V$ : Slurry flow rate, $\mathrm{m}^{3} / \mathrm{hr}$

$l^{\prime}$ : Filtrate volume per unit area of filter, $\mathrm{m}$ or Hydrogen superficial velocity through reactor, $\mathrm{cm} / \mathrm{sec}$

$x_{i}$ : Standardized variables after transformation of coordinates, $i=1 \sim 5$

$x_{i}$ : Dimensionless process variables, $i=1 \sim 5$

\section{Greek letters}

$\alpha$ : Specific cake resistance of filtration, $\mathrm{m} / \mathrm{kg}$

0 : Reaction time for batch reactor, hr or Time for filtration, hr

$\bar{\theta}:$ Mean residence time in continuous reactor, hr $\kappa$ : Diluteness of slurry, $\mathrm{m}^{3} / \mathrm{kg}$ $\mu$ : Viscosity of filtrate, $\mathrm{kg} / \mathrm{m} \mathrm{sec}$

$\Psi$ : Sensitivity of variable to production cost

\section{Abbreviations}

BA: Benzyl Alcohol

MB: Methyl Benzoatc

MeOH: Methanol

TL: Toluene

\section{References}

1) Stecher, P. G., Editor, "The Merck Index", 8th Edition, 137 (1968).

2) Namikawa, K., Petrochemical Engneering (Japan), 1, 1 (1969).

3) Watanabe, M., Namikawa, K., Chem. Eng. Economics Rev., 2, 50 (1970).

4) Japanese Patents Pending.

5) Molstad, M. C., Chemical Engineering (Japan), 27, 41 (1963).

6) Wilde, D. J., Ind. Eng. Chem., 57, 19 (1965).

7) Chu, C., Hougen, O., Chem. Eng. Progress, 57, 51(1961).

8) Kato, K., NMC Research Rept., No. 1528 (1971).

9) Moriguchi, S., Hinshitsukanri (Quality Control), 7, 219, 293 (1956)

10) Komori, K., NMC Research Rept., No. 1520 (1971).

11) Dickey, G. D., "Filtration", 24 (1961) Reinhold, New York.

12) Shide, Y., NMG Research Rept., No. 1526 (1971).

13) Nelson, W. L., "Petroleum Refinery Engineering", 4th ed., 494 (1958) McGraw-Hill, New York. 